\title{
A PSICOSE NA CONTEMPORANEIDADE E SEUS NOVOS SINTOMAS: DO PATHOS AO ORTHOS
}

Rogério Paes Henriques

Professor adjunto do Departamento de Psicologia e do Núcleo de Pesquisa e Pós-Graduação em Psicologia Social da Universidade Federal de Sergipe/ UFS, tutor da Residência Integrada Multiprofissional em Saúde do Hospital Universitário da UFS, psicólogo (1999/Ufes), mestre (2003) e doutor (2008) pelo IMS/Uerj.
RESUMO: Expõe-se aqui a psicose clássica, "freudo-lacaniana", formulada por Lacan, a partir da herança freudiana, em seu ensino linguístico-estrutural na década de 1950, cujo caso paradigmático é Schreber, e a "psicose lacano-milleriana”, surgida com a clínica borromeana de Lacan em meados da década de 1970, com base no sinthoma joyceano, denominada recentemente "psicose ordinária”, segundo a orientação dos teóricos ligados ao Campo Freudiano. Pretende-se estabelecer uma análise comparativa entre esses dois conceitos com ênfase nos seus modos de suplência.

Palavras-chave: Psicose clássica, psicose ordinária, suplência, contemporaneidade.

ABSTRACT: The psychosis in the contemporary and its new symptoms: from pathos to orthos. It explains the Classic Psychosis as formulated by Freud's paradigmatic "Schreber case" and, lately, as developed by Lacan's linguistic-structural teaching, back in the 1950's. It explains also the "neopsychosis" that appeared in the Lacan's Borromean clinic in the 1970's based on the Joycean sinthome, called recently "Ordinary Psychosis", under the guidance of authors related to the Freudian Field. It is intended to establish a comparative analysis between these two concepts with emphasis on their ways of suplency.

Keywords: Classic psychosis, ordinary psychosis, suplency, contemporary. 
"Nunca se considerou nada mais que um ser humano comum, e teria dado qualquer coisa para que seu casamento durasse a vida inteira. (...) Não pretendia ser ninguém excepcional. Era apenas vulnerável, frágil e confuso."

(Philip Roth. Homem comum)

\section{PSICOSE E CONTEMPORANEIDADE}

O atual contexto sócio-histórico insere-se numa discussão acerca do que Lyotard (1998) chamou de "pós-modernidade",, caracterizando-se, dentre outros aspectos, pela incredulidade para com as metanarrativas ou grandes narrativas. Pode-se dizer que Freud e Marx teriam sido os últimos autores modernos a criar metanarrativas, isto é, cada qual ao seu modo instaurou uma nova discursividade fundada em seu nome próprio - daí o famoso movimento empreendido por Lacan de "retorno a" Freud (FOUCAULT, 1992). Partindo-se das possibilidades discursivas assim instauradas, Freud e Marx são autores que podem ser reinventados ad infinitum, como o comprovam suas incessantes e insistentes releituras. Isso só foi possível porque Freud atrelou sua obra psicanalítica ao seu nome próprio, conferindo-lhe um registro autoral e atribuindo-lhe uma dimensão autorreferencial, sem abrir mão de suas pretensões universais. Isto é justamente o que teria se apagado na atualidade com o declínio das teses universalistas e a ascensão dos relativismos pós-modernos; com a "morte do autor", proclamada pela pós-modernidade, sucedeu-se à produção de saber anônima e fragmentada. Basta uma olhadela nos parâmetros atuais de avaliação da produção acadêmica propostos no Brasil para perceber que o modelo privilegiado é o quantitativo da produção científica de massa, em detrimento da produção intelectual autoral qualitativa; tal exigência de produtividade e de anonimato faz supor a existência de pesquisadores "sem-qualidades", no sentido que Jacques-Alain Miller confere a essa expressão de Robert Musil. Na atualidade, quase não há mais homens excepcionais. Praticamente não há mais espaço para um grande nome no pensamento contemporâneo. Como assinala Miller (2003a), no lugar dos grandes inventores, escritores, governantes, políticos e visionários, a cena pública exibe hoje, sem pudor, enorme quantidade de personagens medíocres, de cultura de massa, de governantes impotentes, de políticos corruptos, de homens míopes e manipuladores.

\footnotetext{
${ }^{1}$ Deixarei aos experts a acalorada discussão sociológica sobre a descontinuidade histórica (embutida no conceito de "pós-modernidade") ou continuidade histórica (suposta nas teses sobre a "hipermodernidade", a "modernidade tardia ou avançada" etc.), que o Spätkapitalismus representaria. Fato é que tanto os teóricos "não-continuístas" quanto os "continuístas" apontam para mudanças substanciais que vêm ocorrendo no mundo atual, as quais, se não assinalam uma ruptura qualitativa entre a Era Moderna e um para-além dela, indicam uma alteração quantitativa significativa digna de nota.
} 
O pós-moderno se mostra na desestruturação dos saberes estabelecidos, no anonimato do modo de vida atual, produzindo desarranjos nos laços sociais até então constituídos, além de novos sintomas. Não vivemos mais sob o reinado do pai, nem sob a égide dos ideais; ao declínio da função paterna e à multiplicação do discurso do mestre na contemporaneidade corresponde um sujeito sem referências, desbussolado, disperso no anonimato de uma cultura da mediocridade.

O sujeito se modifica em função das transformações sócio-históricas atuais que privilegiam determinadas formas de experiência e de existência em detrimento de outras possibilidades existenciais (daí a noção de "processo de subjetivação" inspirada em Michel Foucault) ou, em termos lacanianos, as transformações do discurso do mestre na contemporaneidade e a promoção de novos laços sociais implicam novas composições psíquicas e formação de novos sintomas. Suponho aqui que a chamada "psicose ordinária" (lembrando que tal adjetivação pode significar tanto "frequente" quanto "comum", "banal” e, por extensão, "medíocre") seria a modalidade de apresentação prototípica da psicose na contemporaneidade, na era do Outro que não existe. Portanto, um novo protótipo de psicótico teria surgido na atualidade: o indivíduo medíocre e normatizado, dito "ordinário", bem diferente dos "extra-ordinários" loucos célebres, cujo emblema maior é Schreber.

Tal hipótese sustenta-se em duas afirmações de autores ligados ao Campo Freudiano: 1) a de Éric Laurent, na Convenção de Antibes, de que a psicose ordinária seria a psicose da era da democracia, quando levada em consideração a psicose de massa (MILLER et. al., 2009, p.224); 2) a de Jacques-Alain Miller, em Intuições Milanesas, de que o sinthoma, ${ }^{2}$ tal como abordado por Lacan em seu último ensino, corresponderia à fragmentação das entidades clínicas do DSM³ (MILLER, 2003b).

Com esta afirmação de Miller, pode-se deduzir que Lacan aparece como aquele autor antenado com o seu tempo que, em plena efervescência (contra)cultural da década de 1970, começou a pensar uma clínica dos novos sintomas já não pautada numa abordagem clássica das estruturas clínicas bem definidas (neurose, psicose e perversão). De Schreber (LACAN, 1955-56/2002; 1959/1998) a Joyce (LACAN, 1975-76/2007), do estruturalismo linguístico ao pós-estruturalismo

\footnotetext{
${ }^{2}$ O sinthoma (grafado com "th") é um sintoma cuja função é manter juntos o real, o simbólico e o imaginário (R. S. I.). Surge no contexto da "clínica borromeana" ou "segunda clínica lacaniana”, ou seja, da clínica que se ocupa do aparelhamento do gozo e das possibilidades de amarrações entre essas três dimensões da experiência subjetiva.

${ }^{3}$ Da sigla em inglês: Diagnostic and statistical manual of mental disorders (Manual diagnóstico e estatístico dos transtornos mentais), elaborado pela American Psychiatric Association - APA. A sua terceira edição, de 1980, inaugurou uma nova nosografia sindrômica, supostamente descritiva e ateórica, cujo modelo operacional empírico-pragmático fragmentou as antigas “entidades nosológicas" (no sentido kraepeliniano da expressão) que até então constituíam a base dos manuais nosográficos psiquiátricos. Atualmente, estamos na quarta edição revisada desse manual, que segue a mesma metodologia do anterior: DSM-IV-TR, de 2000.
} 
topológico, essa guinada no ensino de Lacan sobre as psicoses, que levaria vinte anos para ser concluída, parece sintomática do novo rumo que ele daria à psicose. Esta se tornou o paradigma da psicanálise no seu último ensino, a partir de suas incursões sobre o que seria futuramente designado por Miller de "foraclusão generalizada" e "pluralização do Nome-do-Pai".

\section{DO SINTOMA AO SINTHOMA}

\section{O sintoma schreberiano}

Pautado numa abordagem estruturalista, Lacan apresenta, na década de 1950, a psicose segundo o viés deficitário, bem ao gosto do saber psiquiátrico do qual era signatário, apesar de seus esforços de afastamento, desde a conclusão de sua tese de doutorado em psiquiatria, de 1932, sobre a "paranoia de autopunição" (LACAN, 1932/1987). Segundo seu sistema linguístico-estrutural, a psicose resulta de uma falha na simbolização que impede a assunção do sujeito falante (ser da linguagem), ${ }^{4}$ remetendo-se à não travessia da epopeia edipiana. Sendo o inconsciente freudiano estruturado segundo as leis da linguagem, há a necessidade da inscrição subjetiva (recalque) de um significante primordial que o fundaria, funcionando como ponto de basta e permitindo os deslizamentos da cadeia significante. Lacan designa tal significante de "Nome-do-Pai" (o pai como símbolo), que representa o pai morto de Totem e Tabu (FREUD, 1913/1996), fundador da interdição. Como terceiro elemento a interditar a relação caprichosa entre a mãe e a criança, o Nome-do-Pai promove a separação entre ambas. Este significante é transmitido à criança pela mãe, vindo metaforizar a sua ausência, isto é, seu desejo, cuja falta é significada pelo operador fálico. Pelo efeito de significação do desejo materno, ou seja, da falta constituinte do ser então transmitida à criança pela mãe (a castração, inscrita como $-\varphi$ ), o falo promove a assunção da diferenciação sexual, deslocando a problemática da criança de "ser o falo" materno para "tê-lo (homem) ou não tê-lo (mulher)". Acontece que, nos casos de psicose, o significante Nome-do-Pai encontra-se foracluído, ${ }^{5}$ acarretando como consequência lógica a elisão da significação fálica $\left(\mathrm{NP}_{0} \rightarrow \Phi_{0}\right)$. Como o falo é

\footnotetext{
4 "Se o neurótico habita a linguagem, o psicótico é habitado, possuído, pela linguagem" (LACAN, 1955-56/2002, p.284).

${ }^{5}$ Galicismo advindo de forclusion, proposto por Lacan como tradução do verbete alemão Verwerfung de Freud (LACAN, 1955-56/2002, p.360). Rabinovitch (2001) assinala que tanto em alemão quanto em francês, “(...) Verwerfung e foraclusão [forclusion] são termos originários da área jurídica” (p.16), usados como referência a um processo cujo prazo legal de recursos já se expirou; afirma, também, que "Foracluir consiste (...) em expulsar alguém para fora das leis da linguagem" (p.17) e que "Verwerfen é jogar fora (werfen) definitivamente (...)” (p.33). O correspondente em português seria "preclusão".
} 
o significante do sexo e da vida, o psicótico, privado dele, estaria desbussolado nas esferas sexual e existencial.

Por não ter acesso ao falo, significante que lhe traz efeito de significação sobre seu sexo, o psicótico se encontra numa problemática fora-do-sexo, pois, não tendo essa referência, ele não se situa na partilha dos sexos. O psicótico é um sujeito ex-sexo, no sentido de sua sexualidade situar-se fora de todo campo demarcável pelo simbólico. Assim, a questão homossexual da paranoia apreendida por Freud (1911/1996), em seu ensaio clínico sobre Schreber, é menos uma causa do que um dos efeitos da falta da inclusão do Nome-do-Pai no Outro. Trata-se, pois, de um fenômeno imaginário que em nada se assemelha à homossexualidade neurótica ou perversa, pois, sendo o psicótico ex-sexo, sua problemática não é homo, mas, como a situa Lacan, transexual, no sentido etimológico do termo: para além dos sexos. Por não ter acesso ao significante que lhe permitiria situar-se como homem na repartição dos sexos e por dever ser o falo, Schreber é levado a situar-se delirantemente do lado da mulher (Girl = Phallus, conforme a equação de Otto Fenichel): “(...) não é por estar foracluído do pênis, mas por ter que ser o falo, que o paciente estará fadado a se tornar uma mulher (...) na impossibilidade de ser o falo que falta à mãe, resta-lhe [a Schreber] a solução de ser a mulher que falta aos homens" (LACAN, 1959/1998, p.571-572). Isto é o que Lacan (1973/2003) caracterizaria, mais tarde, como o efeito do "empuxo-àmulher" da psicose, uma espécie de movimento de retorno: $\Phi_{0} \rightarrow$ A Mulher. ${ }^{6}$ Dessa forma, Schreber veio a se restabelecer por intermédio da modulação de seu "gozo transexual” associado à "coordenada da copulação divina”, isto é, o cultivo de sua volúpia feminina visando à Entmannung ${ }^{7}$ e à redenção do universo (LACAN, 1959/1998, p.575). Com isso, Schreber tornou-se a “mulher de Deus", estabilizando-se nessa metáfora delirante.

A metáfora delirante é o significante que, tal como o Nome-do-Pai, tem a função de ponto de basta, induzindo efeitos de significação. Ela introduz uma ordem no significante, permitindo ao sujeito psicótico ter acesso à significação não-fálica. Nesse sentido, possibilita uma estabilização — porém, sempre precária. Soler assinala que

\footnotetext{
${ }^{6}$ Segundo Lacan, "A Mulher" (a mulher-toda) não possui representação significante, de modo que sua foraclusão do simbólico tende para o psicótico a fazer retorno no real. Ver fórmulas da sexuação (LACAN, 1972-73/1985).

${ }^{7}$ Entmannung é literalmente "castrar"; significa "tirar", "extrair", "arrancar", sentido do prefixo "ent”, o que diz que alguém é "Mann”, isto é, "homem”. Ao traduzir as Memórias de Schreber para a língua portuguesa, Marilene Carone propôs com precisão o termo "emasculação" como tradução de Entmannung; segundo o Dicionário Houaiss da Língua Portuguesa, o verbo "emascular" significa "fazer perder ou perder a virilidade/masculinidade; afeminar(-se)", não se reduzindo à "castração".
} 
"Podemos escrever a metáfora delirante de Schreber e seus efeitos no imaginário. Ali onde faltava o Nome-do-Pai vem o I maiúsculo do ideal, que o próprio Schreber designa pela expressão "ordem do universo" [Weltordnung], e, em seu delírio, Schreber torna-se o esteio, o derradeiro esteio da ordem do universo, I/NP [= Ordem do Universo/ $\left./ \mathrm{NP}_{0}\right]$. No imaginário, na significação, ali onde faltava o falo vem uma significação de suplência que é ser a mulher de Deus $=M$. de Deus $/ \Phi_{0}$. Assim é perfeitamente possível escrevermos, de maneira homóloga àquela como se escreve a metáfora paterna com o algoritmo significante/significado, a metáfora delirante de Schreber. No fundo, essa metáfora tem uma função manifesta de limite. Ela faz o delírio entrar nas fronteiras precisas que o parcializam” (SOLER, 2007, p.201)

Num esforço de esquematização, Quinet (2006, p.143) propõe o seguinte quadro explicativo:

SCHREBER
\begin{tabular}{|l|l|}
\hline IMAGINÁRIO & SIMBÓLICO \\
\hline Eu & Outro \\
\hline Corpo & Deus \\
\hline$\Phi_{0}$ & $\mathrm{NP}_{0}$ \\
\hline Gozo transexual & \\
\hline Transformação em mulher [Entmannung] & Ordem do mundo [Weltordnung] \\
\hline
\end{tabular}

\section{0 sinthoma joyceano}

Como já dito, o ensino de Lacan dá uma guinada na década de 1970. Miller (2009, p.43) assinala que os termos popularizados por ele como "primeiro" e “último" Lacan não implicam sobrepujança de uma teoria sobre a outra, mas antes pressupõem a sobreposição e a coexistência das mesmas, tal como no tipo de formação evocada por Freud acerca da neurose. Fato é que a função paterna perde a majestade nesse novo contexto.

Extraindo as consequências lógicas de sua teorização sobre a incompletude do Outro - escrita por S (A barrado) - e a correlata foraclusão generalizada, o Nomedo-Pai aparece no "último" Lacan como um quarto termo, ligado à nominação, capaz de suplementar os outros três (R. S. I.) e de articulá-los de modo borromeano, na neurose. Como falta a referência no campo da linguagem para todos os seres falantes, o Nome-do-Pai é ele próprio uma suplência, equivalendo-se ao sintoma $\left(\sum \equiv \mathrm{NP}\right)$, na medida em que participa de certa impostura. 
"O Nome-do-Pai não é algo inerente à linguagem, é algo que alguns sujeitos constroem e outros não, e os que o constroem não são menos delirantes que os outros porque o Nome-do-Pai já é um delírio. Acreditar no sentido das palavras é delirante. A partir da foraclusão generalizada, aceitamos o delírio compartilhado que o coletivo nos oferece. Os que não acreditam nisto, os que não acreditam nem no Nome-do-Pai nem nas palavras se enganam menos que os que acreditam, mas o preço a pagar é muito caro. Por isso, Lacan chama seu Seminário XXI, Os não-tolos erram, que em francês [Le non-dupes errent] é homofônico com os Nomes-do-Pai: os que não se enganam, os que percebem a balela do Nomedo-Pai, os que não são tolos neste sentido são condenados a errar, procurando suas próprias soluções por não querer entrar no delírio coletivo. (...) o exemplo mais claro deste delírio coletivo é a premissa universal do falo. O que pode ser mais delirante que a crença infantil de que as mulheres têm pênis? Cada psicótico tem que fazer o seu próprio trabalho para construir seu próprio Outro. O trabalho que o neurótico faz mais facilmente, acreditando num delírio compartilhado, prêt-à-porter, por assim dizer, o psicótico tem que construí-lo sozinho." (JIMENEZ, 2004, p.83, grifos nossos)

A foraclusão do Nome-do-Pai na psicose assinala a carência dessa suplência paterna, a qual pode ser compensada por outras formas de suplência (no âmbito da pluralização do Nome-do-Pai), implicando, todavia, certa degradação de sua função. Eis o preço a ser pago pelo psicótico ao sustentar sua heresia ao Nome-do-Pai! A suplência, escrita pela função $\sum$ (x), é uma invenção singular do sujeito que opera uma pacificação do seu gozo, conservando o traço da falha a qual ela remedia; ela não equivale à castração e malogra em colocar em jogo o falo como operador simbólico. Na psicose de Joyce (suposta por Lacan), por exemplo, seu ego aplainado pelo sinthoma escritural supre a foraclusão do Nome-do-Pai restaurando um nó não borromeano — trata-se do que Lacan denominou de "psicose sinthomatizada”. Segundo Miller, o conceito de psicose ordinária (que abordarei a seguir) acabou por cobrir um campo semântico até então disperso: “a psicose compensada, a psicose suplementada, a psicose não desencadeada, a psicose medicada, a psicose em terapia, a psicose em análise, a psicose que evoluciona, a psicose sinthomatizada" (MILLER et al., 2009, p.201) — em suma: a psicose que "deu certo" devido a algum efeito compensatório estabilizador que evita as vivências psicóticas mortíferas e a passagem ao ato, quer tal efeito tenha sido conquistado pela terapêutica (medicamentosa, analítica, psicoterápica, psicossocial ou outra qualquer), quer não. Desde então, passou-se a denominar a psicose clássica (schreberiana) de "extraordinária", dada sua raridade quando comparada à frequência das psicoses ordinárias na atualidade. Esta reconceitualização da psicose permite sair da lógica do modelo deficitário (foraclusão de um significante no Outro) para sublinhar a conexão do significante e do gozo e, portanto, certa impostura do pai como garantia do Outro. A norma edípica demonstra, assim, 
seu caráter não essencial e sua impotência para regular o gozo pela lei e pelo ideal. A clínica borromeana não possui como garantia o Outro prévio, tratandose, pois, de uma clínica continuísta, ${ }^{8}$ para-além do Édipo; Joyce é um exemplo emblemático de que se pode prescindir do Nome-do-Pai com a condição de dele se servir. Na clínica borromeana, as possibilidades de enodamento dos registros R. S. I. tornam-se o eixo clínico diretivo, que visa o tratamento dos modos de gozo via sinthoma; a ênfase recai nas invenções do sujeito em seu trabalho com a lalíngua, ${ }^{9}$ isto é, em sua capacidade para encontrar uma solução singular com vistas à criação de laço social.

\section{A PSICOSE ORDINÁRIA}

O termo "psicose ordinária” foi cunhado por Jacques-Alain Miller no decorrer de três encontros anuais das Sessões Clínicas francófonas do Instituto do Campo Freudiano, ocorridos no fim da década de 1990 (MILLER et al., 2009, p.200-204).

Se na psicose tradicional tratava-se de desencadeamento, sintomatologia e estabilização clássicas, cujo modelo paradigmático é o de Schreber, a psicose ordinária aproxima-se mais: 1) da "pré-psicose”, tal como denominou Lacan em seu seminário de 1955-56, a psicose latente ou não desencadeada (ao menos não à maneira clássica), muito embora sem se confundir com esta; ${ }^{10}$ 2) da sintoma-

\footnotetext{
${ }^{8}$ No sentido de não haver uma descontinuidade radical entre as "estruturas" neurose e psicose; assinala-se certa continuidade entre ambas na medida em que representam duas saídas diferentes à mesma dificuldade do ser. "Tanto o francamente psicótico como o normal são variações (...) da situação humana, de nossa posição de falantes no ser, da existência do falasser”, assinala Miller (MILLER et. al., 2009, p.202). A clínica borromeana promove uma espécie de igualdade de cada um tanto com relação ao gozo quanto com relação à morte, diluindo as fronteiras entre o normal e o patológico - daí a afirmação de Miller de que a $\Phi_{0}$ e a $\mathrm{NP}_{0}$ são os extremos da curva de Gauss, que apresenta o real das coisas humanas (Idem, p.216).

${ }^{9}$ Em seu seminário Mais, ainda..., Lacan (1972-73/1985) decompôs o conceito de linguagem em duas partes correlativas: lalangue e laço social.
}

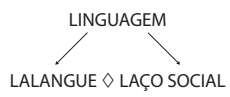

Grosso modo, Lacan designa lalangue (traduzido para o português por "lalíngua" ou "alíngua", caso se queira manter ou não a cacofonia original da expressão neológica francesa, associada à lalação do bebê) ao uso assemântico da língua, pautado na materialidade sonora dos significantes.

10 "A abordagem da psicose ordinária não saberia se confundir com a da pré-psicose (...), pois a psicose clínica não está em germe na estrutura. Ela é somente uma possibilidade que se atualizará eventualmente por ocasião dos maus encontros. A identificação da estrutura psicótica fora do desencadeamento não é redutível ao discernimento dos fatos mórbidos iniciais" (MALEVAL, 2003, p.6; tradução nossa). Não entrarei aqui nos meandros da 
tologia discreta dos "fenômenos de franja ou de borda", que requerem a busca por pequenos sinais de "uma desordem provocada na junção mais íntima do sentimento de vida do sujeito" (LACAN, 1959/1998, p.565) — desordem essa localizada na junção entre o pensamento e o corpo; (3) da ampliação das formas de suplência na psicose (desenvolverei no próximo tópico este último ponto).

Maleval (2003, p.20) assinala que a psicose ordinária requer um diagnóstico duplo para ser identificada: por um lado, a busca por sinais da falha no nó borromeano na estrutura psíquica e, por outro, o esforço inventivo empreendido pelo sujeito para compensar essa falha. ${ }^{11}$

O maior indício para se apreender a estrutura psicótica, segundo Maleval (2003, p.20-33), seriam os traços da não extração do objeto a, ${ }^{12}$ que implica conexões inadequadas do real com o simbólico e o imaginário, revelando a incapacidade de se limitar o gozo. Daí a emergência de um gozo fora do limite fálico, chamado "gozo do Outro" ou "Outro gozo"; trata-se do gozo feminino com o qual o sujeito tende a se identificar como efeito do empuxo-à-mulher, apresentando-se tanto no homem (varia desde a crença em ser homossexual, assumindo uma posição passiva e feminina, à transexualização) quanto na mulher (indo do delírio de tornar-se "A Mulher”, não marcada pela castração, afirmando-se, por exemplo, como "a mãe única e a virgem eterna", ao espectro que abrange desde a impressão de masculinidade até a transexualização). ${ }^{13}$ Representa uma tentativa do sujeito, identificado ao gozo do Outro, de significantizar essa posição, construindo um semblante e escapando assim da melancolização. Por sua vez, a carência da fantasia fundamental provoca efeitos de inconsistência afetiva e corporal, a qual tende a ser compensada pelo sujeito com uma espécie de preocupação obsessiva com a autoimagem (próximo

discussão sobre o desencadeamento ou não das psicoses ordinárias [ver o eixo temático da Convenção de Antibes, O neodesencadeamento, in Miller et. al (2009, p.17-82; p.205-239)]. Assinalo tão-somente que as psicoses ordinárias não se desencadeiam à maneira clássica, segundo a sequência temporal: $1^{\circ}$ ) chamado ao significante foracluído do Nome-do-Pai; $2^{\circ}$ ) formação de $\mathrm{NP}_{0} ; 3^{\circ}$ ) formação de $\Phi_{0}$ (Um-pai $\rightarrow \mathrm{NP}_{0} \rightarrow \Phi_{0}$ ), tal como estabelecido por Lacan na década de 1950.

${ }^{11}$ Se, na década de 1950, Lacan apregoava a primazia do simbólico sobre o real e o imaginário, a partir da década de 1970, abole-se a hierarquização entre os três registros psíquicos e se enfatiza a amarração adicional deles, sendo as falhas nessa amarração, bem como as tentativas de compensá-las, que passam a indicar a presença ou não de psicose.

${ }^{12}$ Na leitura lacaniana, o "objeto a" apresenta duas valências: uma como agalma platônico (objeto causa de desejo) e outra como rebotalho ou dejeto (objeto mais-de-gozar).

${ }^{13}$ Ver o caso clínico "Já não sou uma mulher" (in MILLER et al., 2009, p.177-181) e o breve relato de um caso de transexualidade feminina psicótica (Idem, p.67). 
à dismorfofobia psicótica $)^{14}$ e a correlata compulsão por se examinar diante de superfícies refletoras, designada por sinal do espelho.

Além disso, Maleval (2003, p.33-39) assinala as falhas discretas do ponto de basta, correspondentes à falha no nó do simbólico com o real e o imaginário. Tratam-se dos distúrbios do pensamento e da linguagem, tão enfatizados por Lacan na década de 1950, ${ }^{15}$ os quais, na psicose ordinária, ganham um tom menos exuberante. A ausência de referências fálicas no campo da linguagem e a consequente quebra ou relaxamento da cadeia significante conferem inconsistência ao pensamento e à fala do psicótico ordinário — daí suas frequentes queixas de pensar de modo fragmentado e de emitir uma "fala vazia", por mais que se fale compulsivamente em alguns casos. A questão se desloca aqui da ausente inibição da fala ou do mutismo para o nonsense (o "sentido gozado" como nonsense) que essa fala porta. Devido à falta de conexão entre o gozo e a fala, aparecem fenômenos de irrupção da letra, tais como intrusões de expressões parasitas no pensamento e emergência discreta de vocábulos neológicos na fala. ${ }^{16}$ A discrição desses fenômenos, facilmente confundíveis com o não-patológico, ${ }^{17}$ requer cautela e seu valor semiológico insere-se num contexto mais amplo, associado aos fatores descritos antes como índices da não-extração do objeto a. Destaque, ainda, para as suplências associadas às atividades de escritura, que envolvem o gosto dos psicóticos pelos jogos da letra (palavras-cruzadas e afins, programas de tevê que envolvam números e letras, anagramas, trocadilhos, palíndromos, escrita compulsiva etc.), cujo maior emblema é a escritura de Joyce.

\footnotetext{
${ }^{14}$ Diante dos exemplos clínicos ilustrativos descritos por Maleval, não pude evitar a constatação da semelhança entre eles e o episódio do nariz no caso do Homem dos Lobos, analisado por Sigmund Freud (1918/1996) e Ruth Mack Brunswick (1928/1976). Ver também Escars (2005). Há toda uma discussão na Convenção de Antibes sobre os fenômenos de corpo das psicoses ordinárias, designados "neoconversões", numa aproximação comparativa com as conversões histéricas e com os fenômenos psicossomáticos: ver Miller et. al (2009, p.85128; p.241-274).

15 "Eu me recusei a dar o diagnóstico de psicose [a um caso específico] por uma razão decisiva, é que não havia nenhuma dessas perturbações que constituem o objeto de nosso estudo este ano, e que são os distúrbios na ordem da linguagem. Devemos exigir, antes de dar o diagnóstico de psicose, a presença desses distúrbios" (LACAN, 1955-56/2002, p.109; grifo nosso).

${ }^{16}$ Sobre esse aspecto, ver o caso de Gérard Primeau (ou "Geai Rare Prime Au”) de uma "psicose lacaniana”, apresentada por Lacan (1975/2000), durante uma de suas apresentações de pacientes.

${ }^{17}$ Ver a gafe de Lacan, em seu seminário sobre as psicoses, ao atribuir a um paciente psicótico o suposto neologismo galopiner, quando, de fato, trata-se de um termo regional francês que se encontra em Émile Zola (MILLER et al., 2009, p.212).
} 
Por fim, Maleval (2003, p.39-56) ressalta os transtornos de identidade e a prevalência das identificações imaginárias, índices de uma falha no nó do imaginário em suas conexões com os demais registros:

“(...) parece que um efeito maior da perda da sustentação do eu seja uma propensão deste a se deixar capturar por outras imagens especulares [restrição ao eixo narcísico a-a’ do esquema L de Lacan]; daí a associação frequentemente notada entre os transtornos de identidade e a prevalência das identificações imaginárias” (idem, p.39; tradução nossa)

Mais do que a despersonalização, são os fenômenos de transitivismo nos psicóticos que aparecem no núcleo da clínica da falha e dos esforços de compensação do eu. Em De uma questão preliminar..., Lacan assinala que para impedir a falha da fantasia fundamental, que arrisca deixar o sujeito sem orientação na existência, o psicótico procura por qualquer identificação que lhe permita assumir o desejo da mãe (LACAN, 1959/1998, p.572). As identificações imaginárias não sustentadas pelo "traço unário" (significante mestre) constituem um sinal clínico de primeira ordem, pois respondem aos dois critérios exigidos para o discernimento da psicose ordinária: elas testemunham uma falha subjetiva e a sua compensação. A carência do significante mestre manifesta-se por certa inconsistência das identificações, mas também pelo pouco peso das significações carregadas pelo sujeito, o que alguns autores traduzem por um sentimento de ser vazio. Ao não se orientar sobre um ideal comandado pelo significante mestre, o sujeito encontra-se perdido em sua própria existência, alienando-se de bom grado ao outro especular. Tais sujeitos aproximam-se do modo de funcionamento "como se", descrito por H. Deutsch, tendo como ponto comum entre si a espantosa plasticidade das identificações, algo semelhante ao que Miller designou por “ser puro semblante” (MILLER et. al., 2009, p.29). Assim, uma relação amorosa bem-sucedida, um devotamento ao trabalho ou aos estudos, a participação em seitas e em partidos políticos, a opção pela rígida carreira militar ou religiosa, todas essas normatizações contribuem com identificações imaginárias estáveis, que permitem ao psicótico enquadrar sua existência e evitar o desencadeamento clássico de sua psicose. E as identificações são tanto mais estáveis quanto mais elas portem o ideal e estejam em conexão com o real, limitando e localizando o gozo do psicótico.

A novidade trazida pelo conceito de psicose ordinária, segundo Maleval (2003, p.7), é o foco na singularidade das suplências construídas pelos sujeitos psicóticos, que permitem sua compensação evitando o desencadeamento clássico; 
ou seja, enfoca-se o processo singular mediante o qual cada falasser ${ }^{18}$ constrói $^{2}$ sua suplência.

\section{AS NEOSSUPLÊNCIAS: DO SIGNIFICANTE Ȧ LETRA}

Em seu sentido amplo, entende-se suplência como sinônimo de sinthoma, isto é, daquilo que mantém juntos o R., o S. e o I., incluindo nesse escopo o Nomedo-Pai. Já em seu sentido estrito, a suplência nas psicoses fala de um singular modo de tratamento significante do gozo do Outro; na ausência do Nome-do-Pai, tratar de servir-se dele enquanto função de nominação. É o que ocorre com Joyce, por exemplo:

"O sinthoma, o ego produzido por Joyce, vem reparar o erro no próprio lugar onde ele é produzido. O ego de Joyce é uma invenção literária. É o Nome-do-Pai no qual ele se apoia e utiliza justamente para fazer um nome. Com sua obra, com a ajuda da escrita em que o significante vem preencher o significado, ele fabrica o tecido imaginário que para ele não se sustentava no simbólico” (SKRIABINE, 2009, p.6)

As psicoses ordinárias contemporâneas trazem à baila "novas suplências" ou "neossuplências", cujas especificidades residem não mais no tratamento do gozo com recurso ao significante, como em Joyce (via “obra”), mas sim com recurso à letra.

\section{Das muletas imaginárias às bricolagens duvidosas}

Em sua descrição do typus melancholicus, Tellenbach (1976) assinalou a "sobreidentificação com os papéis sociais" como uma de suas características mais marcantes. Castanet \& De Georges (in MILLER et. al., 2009, p.40) destacam ser essa uma espécie de "suplência intercrítica" na melancolia, ${ }^{19}$ cuja fórmula se escreveria da seguinte maneira:

$$
\frac{\text { i }\left(S, S^{\prime}, S^{\prime \prime}, S^{\prime \prime \prime} \ldots\right)}{\text { Nome próprio }}
$$

18 Parlêtre, em francês, conceito introduzido por Lacan no seu Seminário 22: R.S.I. (inédito), que condensa a forma verbal "parle" ("fala") e o verbo "être" ("ser/estar"). Ao transformar o l'être parlant (sujeito do inconsciente) em parlêtre (falasser) promove-se uma incorporação, aos efeitos do significante enquanto significação, dos efeitos do significante como afeto, isto é, de seus efeitos no corpo, cujo emblema é o gozo. A expressão falasser condensa o sujeito do significante com a substância gozante, e inclui na noção de sujeito o corpo.

${ }^{19}$ Cabe ressaltar que a melancolia é considerada uma psicose atípica, sobretudo com relação aos seus modos de desencadeamento, aproximando-se, portanto, dos desligamentos e religamentos típicos das psicoses ordinárias. 
Contudo, a sobreidentificação não se confunde com o ideal do eu; antes, representa o ideal de uma norma social encarnada ao pé da letra. Como assinala Éric Laurent, "a sobreidentificação normal sublinha que a norma de identificação está louca” (Idem, p.225). François Morel afirma que a identificação estaria do lado do significante, sendo flutuante, enquanto que a sobreidentificação teria um caráter fixo, estando do lado da letra:

"Na identificação, o sujeito desempenha um papel, e sabe que o desempenha, pode então distanciar-se, pode apagar-se a respeito de seu papel. Na sobreidentificação, o sujeito é esse papel; se deixa de sê-lo, se entra em contradição com esse papel, já não é nada, e efetivamente desencadeia sua crise (...)” (Idem, p.236; tradução nossa)

Nesse sentido, afirma Skriabine, acerca das psicoses ordinárias:

"Conformar-se à forma perfeita, a ter o ar absolutamente normal, a comportar-se na vida quotidiana sem problemas particulares, não implica amarração. Se eu puder ousar, utilizarei esta metáfora: algumas gotas de cola ou mesmo dois ou três pedaços de fita durex podem ser suficientes. R, S e I parecem se sustentar bem juntos, até demais. O sujeito tem, às vezes, um aspecto excessivamente conveniente; não há qualquer margem entre o modelo socialmente esperado e a aparência do sujeito. Não vemos mais o sujeito, somente a aparência à qual ele se conforma. (...) Mas, esta ilusão, geralmente, não pode durar muito tempo, nem resistir a uma situação realmente conflituosa. Esses sujeitos mostram-se de repente particularmente preocupados com o olhar dos outros sobre eles. A menor discordância no olhar outro sobre o sujeito é o mesmo que olhar do Pai que surge, e o sujeito desmorona" (SKRIABINE, 2009, p.9-10; grifo nosso).

Deduz-se que a psicose ordinária aproxima-se do que alguns psicanalistas vêm chamando de "normopatias" (conceito cunhado por Joyce McDougall) ou patologias da normalidade ${ }^{20}$, caracterizadas pela sobreidentificação dos indivíduos com a norma social e seus estereótipos. Não é à toa que, como já dito, Éric Laurent acentuou ser a psicose ordinária a psicose massificada da atual era democrática (in MILLER et. al., 2009, p.224). Nesses casos, a pseudonormalidade vem a ser o sinthoma que, concomitantemente, denuncia a falha no nó borromeano e representa a tentativa de repará-la, por intermédio da hiperadaptação à norma social.

Arrisco-me a dizer que a psicose ordinária é a psicose da era da biopolítica (FOUCAULT, 2008), na qual o discurso do capitalista, ${ }^{21}$ sob a égide da gover-

\footnotetext{
${ }^{20}$ Ver Ferraz (2002). Trata-se aqui de mera aproximação e não de confusão entre tais conceitos.

${ }^{21}$ Lacan usou a expressão discurso do capitalista para se referir à contemporaneidade. O discurso do capitalista mostra a modificação do discurso do mestre efetuada pela ciência.
} 
namentalidade neoliberal, reduz a vida a sua forma nua 22 (AGAMBEN, 2002), produzindo indivíduos autômatos e rastejantes. Perante a dificuldade generalizada de transmutar a própria “dor” em "sofrimento" (pathos) na atualidade devido à carência de intermediação simbólica para tal (BIRMAN, 2003), o psicótico ordinário rasteja entre os produtos biotecnológicos (com destaque ao arsenal medicamentoso promovido pelos sedentos laboratórios farmacêuticos), tornando-se um indivíduo robotizado atado ao orthos ("reto”, “direito”, “correto”, "normal” etc.).

\section{CONSIDERAÇÕES FINAIS}

Schreber construiu sua suplência via "metáfora delirante", assumindo o lugar da exceção (A mulher de Deus) por intermédio de toda uma complexa construção delirante que visa a colocar o imaginário ali onde falta o significante primordial. Marie-Helène Brousse assinala que a expressão "ordinária”, que qualifica a psicose contemporânea, refere-se, também, a "comum”, “banal”, “não excepcional”, no sentido do psicótico ordinário não se colocar no lugar da exceção que falta, a exceção do "pai que nomeia”, faltante; assim, em seu delírio, extraordinário, Schreber se tornou $A$ mulher que falta a Deus, tal como se pode encontrar outros pacientes que se devotam a ser o homem que pode seduzir ou satisfazer todas as mulheres. Essas posições de exceção correspondem à chamada "psicose extraordinária”. Na psicose ordinária, os pacientes não se consagrariam a encarnar, eles próprios, a função de exceção que falta na organização simbólica (BROUSSE, 2009, p.7). As psicoses extraordinárias são, em alguma medida, respostas à exceção; ao contrário, a psicose ordinária não está indexada à exceção, mas procede de uma identificação à normalidade. Assim, as novas suplências, ordinárias, no âmbito da pluralização do Nome-do-Pai e da passagem do Um ao múltiplo, já não se condensam em metáforas delirantes, mas sim se deslocam em metonímias literais, com o correlato abandono do esforço de significação.

Segundo a Convenção de Antibes, o manejo clínico das psicoses ordinárias refletiria um trabalho de tradução (uma espécie de "esforço de poesia”) da lalíngua do paciente com vistas ao enlaçamento social. Como assinala Danièle Rouillon: "A partir de um significante bruto, chegar a um $\mathrm{S}_{1}$ civilizado, simpático, que fosse talvez, então, uma metonímia literal” (in MILLER et al., 2009, p.308). O foco incide em $\mathrm{S}_{1}$ isolado da cadeia significante; com isso, enfatiza-se o tratamento

\footnotetext{
Assim, pode-se falar num sintoma moderno, no qual o sujeito procura sua completude no consumo de objetos. Este modo de complementação do sujeito, alienando-o no consumo, fez Lacan dizer que o discurso do capitalista rejeita a castração.

${ }^{22}$ Os antigos gregos tinham duas expressões distintas para referirem-se ao que entendemos hoje por "vida": zoe (a vida nua no seu anonimato) e bios (a vida qualificada do cidadão). O biopoder é o operador primordial da vida nua (zoe), que apaga os traços da vida qualificada (bios) na contemporaneidade.
} 
do gozo a partir da letra, isto é, do significante não articulado, que não significa nada, em detrimento da significação. Schreber pôde buscar a função do Nomedo-Pai sob a forma do ideal, do indivíduo excepcional; Joyce, por intermédio de sua obra excepcional, conseguiu inscrever seu nome-de-gozo; já aos psicóticos ordinários contemporâneos, imersos numa cultura da mediocridade, resta-lhes a solitária errância metonímica, em seu périplo rumo à sustentação de si: é como pintar a tristeza, um semblante sem coraçã, inspirada em um poema de Paul Éluard, "Apenas desfigurada", cuja última estrofe é "tristeza belo rosto").

Recebido em 3/11/2010. Aprovado em 2/4/2011.

\section{REFERÊNCIAS}

AGAMBEN, G. (2002) Homo Sacer: o poder soberano e a vida nua I. Belo Horizonte: Editora da UFMG.

BIRMAN, J. (2003) Dor e sofrimento num mundo sem mediação. Estados Gerais da Psicanálise: II Encontro Mundial, Rio de Janeiro. Acesso em: 16/09/2010. Disponível em: http://www.estadosgerais.org/mundial_rj/download/5c_Birman_02230503_port.pdf.

BROUSSE, M-H. (2009) A psicose ordinária à luz da teoria lacaniana dos discursos, in Latusa digital, ano 6, n.38, p.01-16.

BRUNSWICK, R. M. (1928/1976) “Suplemento a la 'Historia de una neurosis infantil' de Freud”, in GARDINER, M. El hombre de los lobos por el hombre de los lobos. Buenos Aires: Nueva Visión.

ESCARS, C. (2005) “O homem dos diagnósticos da história de um dilema lacaniano”, in Psicoses, ano XXIV, n.36. Rio de Janeiro: Escola Letra Freudiana, p.121-142.

FERRAZ, F. C. (2002) Normopatia. São Paulo: Casa do Psicólogo.

FOUCAULT, M. (1992) O que é um autor? Lisboa: Vega editora. . (2008) Nascimento da biopolítica. São Paulo: Martins Fontes.

FREUD, S. (1996) Edição standard brasileira das obras psicológicas completas de Sigmund Freud. Rio de Janeiro: Imago.

(1911) "Notas psicanalíticas sobre um relato autobiográfico de um caso de paranoia (dementia paranoides)" v.XII, p.15-89

(1913) “Totem e Tabu” v.XIII, p.13-162.

(1918) “História de uma neurose infantil” v.XVII, p.15-129.

JIMENEZ, S. (2004) “Clínica Lacaniana — foraclusão generalizada”, in MURTA, A., MURTA C. e MARTINS, T. (org.). Incidências da psicanálise na cidade. Vitória: Edufes.

LACAN, J. (1932/1987) Da psicose paranoica em suas relações com a personalidade. Rio de Janeiro: Forense Universitária. 
(1955-56/2002) O Seminário, livro 3: as psicoses. 2 ed. rev. Rio de Janeiro: Jorge Zahar.

(1959/1998) "De uma questão preliminar a todo tratamento possível da psicose”, in Escritos. Rio de Janeiro: Jorge Zahar, p.537590.

(1972-73/1985) O Seminário, livro 20: mais, ainda. Rio de Janeiro: Jorge Zahar.

(1973/2003) "O aturdito", in Outros Escritos. Rio de Janeiro: Jorge Zahar, p.448-497.

(1975/2000) "Uma psicose lacaniana: entrevista conduzida por Jacques Lacan”, in Opção Lacaniana, n.26/27. São Paulo, p.5-16.

(1975-76/2007) O Seminário, livro 23: o sinthoma. Rio de Janeiro: Jorge Zahar.

LYOTARD, F. (1998) A condição pós-moderna. São Paulo: José Olympio.

MALEVAL, J-C. (2003) Elements pour une apprehension clinique de la psychose ordinaire. Séminaire de la Découverte Freudienne. 18-19 janvier 2003. Acesso em 30/06/2010. Disponível em: http://w3.erc.univ-tlse2.fr/ pdf/elements_psychose_ordinaire.pdf.

MILLER, J-A. (2003a) Le neveu de Lacan. Paris: Verdier.

(2003b) "Intuitions milanaises (2)", in Mental - Revue Internationale de Santé Mentale et Psychanalyse Appliquée, n.12. Paris: Nouvelle École Lacanienne, p.17. Zahar

(2009) Perspectivas do Seminário 23 de Lacan. Rio de Janeiro: Jorge

MILLER, J-A. et al. (2009) La psicosis ordinaria: la convención de Antibes. $4^{a}$ reimp. Buenos Aires: Paidós.

QUINET, A. (2006) Psicose e laço social: esquizofrenia, paranoia e melancolia. Rio de Janeiro: Jorge Zahar.

RABINOVITCH, S. (2001) A foraclusão: presos do lado de fora. Rio de Janeiro: Jorge Zahar.

SCHREBER, D. P. (1903/1995) Memórias de um doente dos nervos. Rio de Janeiro: Paz e Terra, 1995.

SKRIABINE, P. (2009) "A psicose ordinária do ponto de vista borromeano”, in Latusa digital, ano 6, n.38, p.01-12.

SOLER, C. (2007) "Estabilização da psicose”, in O inconsciente a céu aberto da psicose. Rio de Janeiro: Jorge Zahar.

TELLENBACH, H. (1976) Melancolía: visión histórica del problema. Madrid: Morata.

Rogério Paes Henriques

rsphenriques@hotmail.com 